\title{
AZ66: How Can We Play with Emotions?
}

\author{
Stéphan Froment ${ }^{1}$, Mélanie Ginibre ${ }^{1}$, Stéphanie Mader ${ }^{1}$, Antoine Sarafian ${ }^{1}$, \\ Aymeric Schwartz ${ }^{1}$, Delphine Soriano ${ }^{1}$, Alexandre Topol ${ }^{2}$, and Jérôme Dupire ${ }^{2}$ \\ ${ }^{1}$ ENJMIN - 121, rue de Bordeaux \\ 16000 Angoulème, France \\ ${ }^{2}$ CNAM - CEDRIC - 292, rue St Martin \\ 75003 Paris, France \\ \{topol, dupire\}@enam.fr
}

\begin{abstract}
Since the early 90's, affective computing researches have mainly been focused on emotions recognition and less on original entertainment contents that could be proposed. We present a prototype resulting from the association of a physiological sensing device with an original game.
\end{abstract}

Keywords: video game, affective interaction, physiological sensors.

\section{Related Works}

Since the precursor work of Picard in the 90's [1] many researches were conducted in the affective computing field. First of all, physiological aspects were studied to determine which variables are interesting to be monitored. Then, patterns for recognizing specific emotions were revealed by looking to variables' variations in particular situations. Since then, the hardware needed to monitor humans became smaller, more accurate and even wireless [2]. The researches led to numerous fields of application, from health care [5] to entertainment computing [6, 7].

Using the physiological information to disturb the game, adapt its contents and even manipulate the player is quite interesting, in a game validation process. It would be very useful for a game development team to be able to test some particular aspects of the gameplay, from the early development stages. We present in this paper such a game (prototype) born from the association of a physiological sensing device with an original virtual reality game.

\section{AZ66}

The physiological monitoring device was built by us [8]. We designed a hardware which is able to monitor the heart signal (EKG), the galvanic skin response (GSR) and the temperature (TEMP). Thanks to a socket mechanism (Fig.1), all the data is transmitted wirelessly and integrated into the Unreal Engine 3. The interactions remain typical (through the keyboard and the mouse) and only the monitoring hardware differs from a usual playing environment. 

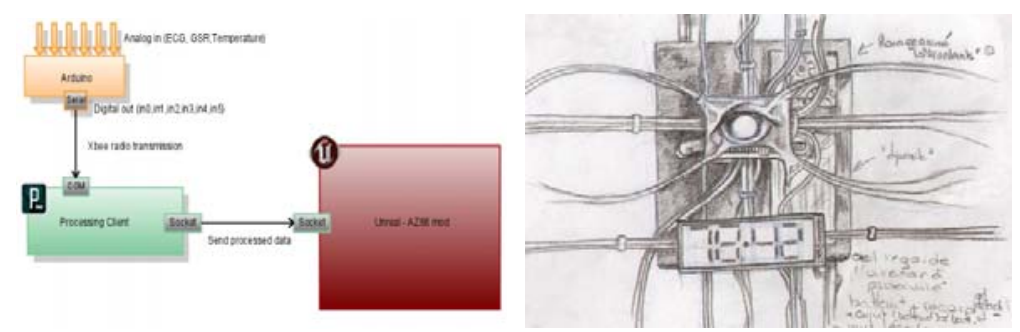

Fig. 1. Hardware and software architecture and artwork

The story brings the player to pass three tests with his physiological states being taken into account. The originality of this game is that the player thinks he always has the control on the game because he has (sometimes fake) bio-feedbacks:

- Defuse the Bomb: this situation is expected to be the most stressful since bio feedbacks are fake and not taken into account. The user is powerless.

- Shoot the Enemy: the number of enemies is proportional to the player arousal level (GSR) and heart rate.

- Exit the Maze: bio feedbacks are taken into account to disturb the player.

At the end of the game, the player gets a global feedback, including his lot in the story and showing how his (real) body reacted during the game, linking the events to the different challenges.

Beyond the rich interaction provided by the dynamic adaptation of game, we expect to design a game validation tool. It will allow the game development team to compare the effective effects of a specific gameplay with the expected ones.

\section{References}

1. Picard, R.W.: Affective computing. MIT Press, Cambridge (1997)

2. Sung, M., Pentland, A.: Minimally-Invasive Physiological Sensing for Human-Aware Interfaces. In: HCI International, Las Vegas, Nevada, USA (2005)

3. Loriga, G., Taccini, N., De Rossi, D., Paradiso, R.: Textile Sensing Interfaces for Cardiopulmonary Signs Monitoring. In: IEEE Engineering in Medicine and Biology Conference, Shanghai, China (2005)

4. Weber, W., Glaser, R., Jung, S., Lauterbach, C., Stromberg, G., Sturm, T.: Electronics in Textiles: The Next Stage in Man Machine. In: 2nd CREST Workshop on Advanced Computing and Communicating Techniques for Wearable Information Playing Interaction, Nara, Japan (2003)

5. Lisetti, C., Lerouge, C.: Affective Computing in Tele-home Health. In: 37th Hawaii International Conference on System Sciences (2004)

6. Matt, J.S.: Relax to Win - Treating children with anxiety problems with a biofeedback videogame (2003),

http: / /medialabeurope.org/research/library/

Sharry_Relax_2003.pdf

7. Magerkurth, C., Cheok, A.D., Mandryk, R.L., Nilsen, T.: Pervasive games: bringing computer entertainment back to the real world. Comput. Entertain. (2005)

8. Dupire, J., Gal, V., Topol, A.: Physiological Player Sensing: New Interaction Devices for Video Games. In: International Conference on Entertainment Computing, Pittsburgh (2008) 